\title{
It is better to smile to women: Gender modifies perception of honesty of smiling individuals across cultures
}

\author{
Kuba Krys ${ }^{1}$ \\ Karolina Hansen² \\ Cai Xing ${ }^{3}$ \\ Alejandra Domínguez Espinosa ${ }^{4}$ \\ Piotr Szarota ${ }^{1}$ \\ María Fernanda Morales 4
}

\begin{abstract}
Social perception studies have revealed that smiling individuals are perceived more favourably on many communion dimensions in comparison to nonsmiling individuals. Research on gender differences in smiling habits showed that women smile more than men. In our study, we investigated this phenomena further and hypothesised that women perceive smiling individuals as more honest than men. An experiment conducted in seven countries (China, Germany, Mexico, Norway, Poland, Republic of South Africa and USA) revealed that gender may influence the perception of honesty in smiling individuals. We compared ratings of honesty made by male and female participants who viewed photos of smiling and nonsmiling people. While men and women did not differ on ratings of honesty in nonsmiling individuals, women assessed smiling individuals as more honest than men did. We discuss these results from a social norms perspective.
\end{abstract}

Keywords: Smile - Social perception - Honesty - Gender - Culture - Impression formation

Smiling seems to endow people with trustworthiness: Others interpret a smile as a signal that this is an honest person (Hess, Beaupré, \& Cheung, 2002). Numerous studies support the general hypothesis that those who smile are rated as more communal in comparison to those who do not smile (e.g., Krumhuber, Manstead, $\&$ Kappas, 2007). On the one hand women are expected to be more communal and expressive than men (Brody \& Hall, 2008); they are more sensitive to nonverbal communication (Hall, 1984) and they smile significantly more than men (LaFrance, Hecht, \& Paluck, 2003). On the other hand various cultural differences in the perception of smiling individuals are described (Szarota, 2011). Although previous studies confirmed that smiling increases perceived honesty in our study we tested the hypothesis that gender and culture as well as their interaction may modify this general pattern

\section{Smile and communion}

Numerous studies support the thesis that smiling individuals are rated higher on communion-related traits: Smiles compared to a neutral facial expression increase ratings of likability (Krumhuber et al., 2007; Lau, 1982), friendliness and warmth (Lau, 1982), honesty (Otta, Lira, Delevati, Cesar, \& Pires, 1994), sociability (Matsumoto \& Kudoh, 1993), trustworthiness (Krumhuber et al., 2007), as well as optimism, conciliation, calmness, reliability, happiness, attractiveness, likability and kindness (Hess et al., 2002; Otta et al., 1994). Moreover, smil-

Correspondence should be addressed to Kuba Krys, Institute of Psychology, Polish Academy of Sciences, Warszawa 00-378, Poland. (E-mail: kuba@krys.pl).

Parts of this research were supported by the National Science Centre grant 2011/03/N/HS6/05112 awarded to Kuba Krys. Norwegian part of this project was completed with the support granted to Kuba Krys by Iceland, Liechtenstein and Norway by means of co-financing from the European Economic Area Financial Mechanism and the Norwegian Financial Mechanism as part of the Scholarship and Training Fund. German part of the project was completed with the support granted to Karolina Hansen in the programme ProExzellenz of the German state of Thuringia. The writing of this paper by Karolina Hansen was supported by the post-doctoral internship "Fuga" awarded to her by the Polish National Science Centre (DEC-2013/08/S/HS6/00573). Chinese part of the project was completed with the support granted to Cai Xing by National Natural Science Foundation of China (grant no. 31200788). Authors would like to express their gratitude to all partners engaged in translations and data collection, especially to: Bjørn Ekelund, Claudia Niedlich, Mark Price, Magdalena Rychłowska, Veronika Sandanger, Sebastian Wilfling and Miao-miao Yang. They also thank the editor Professor Rainer K. Silbereisen and two anonymous reviewers for their comments on the earlier drafts of this manuscript.

1 Institute of Psychology, Polish Academy of Sciences, Warsaw, Poland

2 Faculty of Psychology, University of Warsaw, Warsaw, Poland

3 Department of Psychology, Renmin University of China, Beijing, China

4 Psychology Department, Iberoamerican University, Mexico City, Mexico 
ing individuals elicit more cooperative behaviours and affiliative signals from others (e.g., Gonzaga, Keltner, Londahl, \& Smith, 2001) than people who do not smile. We did not find any study indicating that smiling may negatively affect ratings of communion in comparison to nonsmiling.

\section{Smile and gender}

There is considerable support for the idea that the "default" option for women is to smile and for men not to. Meta-analyses conducted by LaFrance et al. (2003) and by Hall (1984) support the thesis that women smile reliably more than men $(d=.41$ and $d=.63$, respectively). Furthermore, women in general are more attuned to nonverbal behaviour than men (Hall, 1984) with a meta-analysis showing that women in particular are better at decoding nonverbal cues than men (McClure, 2000). Furthermore, social judgements may be affected by gender-based expectations. According to social norms theory, women are expected to be more communal and expressive than men and also more cooperative, kind to others and protective of social harmony (e.g., Brody \& Hall, 2008). We expected that the gender differences above in both smiling and detection of nonverbal cues might imply that men and women differ in sensitivity to smiling facial expressions. Furthermore, social norms theory indicates that women should be more reactive to communal signals what may lead to potentially higher increases of perceived honesty in smiling individuals among women than among men. We predicted a larger effect for smiling on women's than on men's perception of others as communal and honest.

\section{Smile and culture}

Due to cultural diversity in emotional expressiveness, we decided to include culture as an independent variable in our study. Research on cultural diversity in social perception of intelligence in smiling individuals shows that it can vary across cultures (Krys, Hansen, Xing, Szarota, \& Yang, 2014). Hofstede claims (2001) that culture is a system of shared values and beliefs that represent a set of the most frequent reactions of citizens with a common "mental programme". He derived six dimensions to describe a variety of norms and values across nations; the issue of expression or inhibition of emotions is described by the dimension of uncertainty avoidance (UA) (Basabe et al., 2000). Cultures that avoid uncertainty emphasise emotional normativeness: High-UA compared to low-UA societies are more emotional in general and positive emotions are more socially desirable and negative emotions are particularly undesirable in high-UA societies (Basabe et al., 2000).
We predicted that if Hofstede's UA describes cultural diversity of emotional expressiveness and in particular desirability of positive emotions, smiling individuals may be perceived more positively in general and more honest in particular in cultures with high-UA than in cultures with low-UA. The concept of cultural UA was explored not only by Hofstede, but also in the GLOBE project by House, Hanges, Javidan, Dorfman, and Gupta (2004). Therefore, when selecting cultures for our study, we decided to utilise both Hofstede's and GLOBE's approaches for measuring UA.

\section{METHOD}

We explored gender and culture differences in the social perception of honesty in smiling individuals. We chose USA, Norway, Republic of South Africa and China to represent cultures low on Hofstede's UA dimension (one standard deviation below the average UA) and Poland and Mexico to represent cultures high on UA (one standard deviation above the average). We also collected data in Germany, which is described as a society with one of GLOBE's highest UA practices ratings (like China); Poland represents societies low on the GLOBE's UA practices dimension. Similar to Hofstede (2001), we treated country samples as culture samples.

\section{Participants}

In this research, 688 students participated originating from: Renmin University of China (China; 54 female [F], 62 male [M]); University of Jena (Germany; 37 F, 42 M), Universidad Iberoamericana Ciudad de México (Mexico; 68 F, 68 M), University of Bergen (Norway; 56 F, 38 M), University of Łódź (Poland; 55 F, 20 M), University of Cape Town (South Africa; 57 F, 53 M) and University of Wisconsin-Madison (United States; 55 F, 23 M). The mean age across different samples ranged between 20.70 and 22.86 years (China 22.86; Germany 22.11; Mexico 21.07; Norway 22.22; Poland 22.70; SA White 20.76; SA non-White 21.04; USA 21.62). Correlations with the age and the analysed dependent measures were not significant: .003<r<.047 ( $p s>.29)$.

\section{Materials and procedure}

Participants were asked to rate four smiling and four nonsmiling faces of various ethnicities (the need for ethnical diversity is stressed by Matsumoto \& Kudoh, 1993) on four 7-point $(1=$ trait doesn't fit at all to $7=$ trait fits perfectly) Likert-type scales measuring honesty. The questionnaire, in the form of a small booklet, started with the following instructions: Research shows that people can quite accurately evaluate others based on their looks. Can 


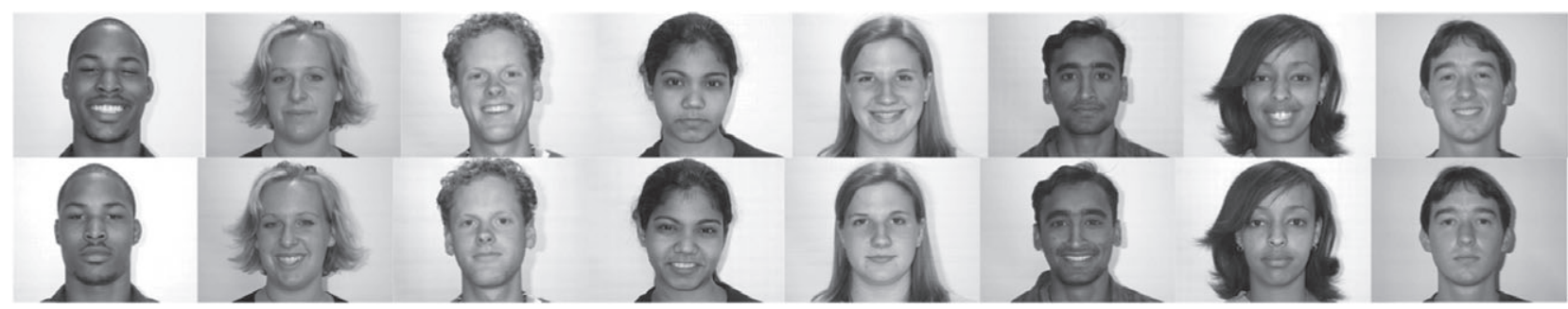

Figure 1. Two sets of photos (miniatures) assessed by participants.

you help us and rate some faces? The following pages of the booklet displayed either deliberately non-dominantly smiling ${ }^{1}$ or nonsmiling faces of eight different individuals (see Figure 1). Photos were drawn from the Center for Vital Longevity Face Database (Minear \& Park, 2004) and were split into two sets: Individuals smiling in one set were presented as nonsmiling in the other set. Photos in each set were randomised. Materials were written in Polish and English, and were translated into the languages of each country studied: Mandarin (China), German, Spanish (Mexico), Norwegian, Polish and English (for the South Africa and the USA samples).

Four independent measures included the smile of the perceived individual (present vs. absent), the culture of origin of participants, participants' gender and target's gender. The dependent variable was perceived honesty of the target individual measured with four items: honest, authentic, and reversed unnatural and false. Perceived 4-item honesty measures had satisfactory reliability in each analysed sample (China $\alpha=.85$; Germany $\alpha=.76$; Mexico $\alpha=.82$; Norway $\alpha=.70$; Poland $\alpha=.79$; South Africa $\alpha=.76$; USA $\alpha=.90$ ).

\section{RESULTS}

To test our hypotheses regarding gender and cultural differences in social perception of smiling individuals, we conducted a 2 (smile present or absent) $\times 7$ (culture) $\times 2$ (gender of observer) $\times 2$ (gender of target) mixed ANOVA, with the smile and gender of target as within-subjects factors and the culture and gender of observer as between-subjects factors.

There was a main effect of culture, $F(6,613)=5.89$, $p<.001, \eta_{\mathrm{p}}{ }^{2}=0.06$, which indicated levels of perception of honesty differed across cultures. Furthermore, a main effect of smile, $F(1,613)=97.42, p<.001, \eta_{\mathrm{p}}{ }^{2}=0.14$, showed that in general participants rated smiling individuals $(M=4.94 ; S D=0.76)$ as more honest than nonsmiling ones $(M=4.62 ; S D=0.70)$. A main effect of participants' gender, $F(1,613)=21.19, p<.001, \eta_{\mathrm{p}}^{2}=0.03$, indicated that female participants rated overall honesty of all targets

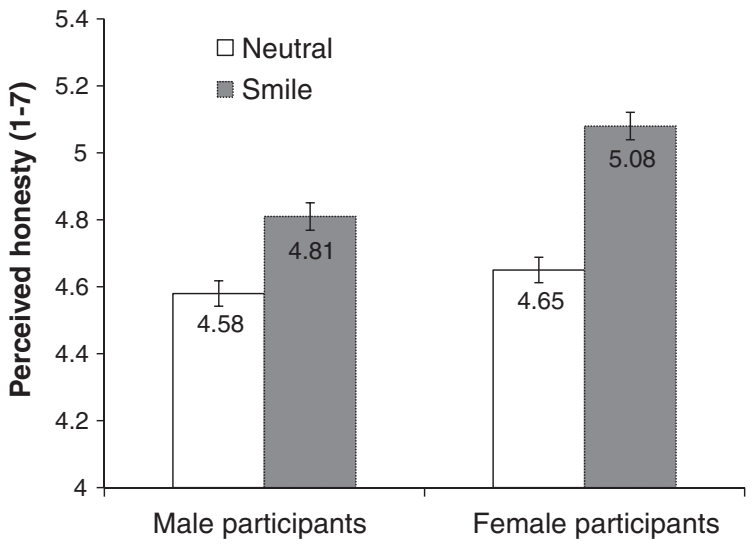

Figure 2. Perceptions of honesty of smiling and nonsmiling people by participants' gender.

as higher $(M=4.89 ; S D=0.60)$ than male participants did $(M=4.66 ; S D=0.60)$. There was no main effect of target's gender, $F(1,613)=1.95, p=.16$.

As predicted, we observed a two-way smile*gender of participant interaction, indicating that processes of social perception of honesty in smiling individuals differs between genders, $F(1,613)=10.40, p=.001, \eta_{\mathrm{p}}{ }^{2}=0.02$ (see Figure 2). On the one hand, women and men did not differ in their ratings of honesty in nonsmiling individuals, $t(654)=1.36 ; p=.18$. On the other hand, women evaluated smiling individuals as more honest than men, $t(648)=4.68 ; p<.001$. Comparisons between ratings of smiling and nonsmiling individuals performed for each gender separately indicated that smiling individuals were rated as more honest than nonsmiling ones by both females, $t(354)=11.18 ; p<.001 ; d=.59$, and males, $t(279)=4.68 ; p<.001 ; d=.28$. These results indicated that both men and women perceived smiling individuals as more honest than nonsmiling ones, but as predicted the increase in ratings was higher for women than men.

Furthermore, a smile*gender of target interaction, $F(6$, $613)=4.08, p=.044, \eta_{\mathrm{p}}^{2}=0.01$, indicated that nonsmiling women were rated as somewhat more honest

\footnotetext{
${ }^{1}$ Presented smiles were deliberate-when photographed, target individuals were asked to smile (Minear \& Park, 2004). All the smiles were friendly-looking and non-threatening.
} 
TABLE 1

Differences in ratings of honesty of smiling and nonsmiling individuals in seven examined cultural samples divided by the gender of participants

\begin{tabular}{|c|c|c|c|c|c|c|c|c|}
\hline \multirow[b]{3}{*}{ Sample } & \multicolumn{4}{|c|}{ Faces } & \multirow[b]{3}{*}{$t$} & \multirow[b]{3}{*}{$d$} & \multirow[b]{3}{*}{$d f$} & \multirow[b]{3}{*}{$p$} \\
\hline & \multicolumn{2}{|c|}{ Nonsmiling } & \multicolumn{2}{|c|}{ Smiling } & & & & \\
\hline & $M$ & $S D$ & $M$ & $S D$ & & & & \\
\hline \multicolumn{9}{|c|}{ Gender of participants: female } \\
\hline China & 4.63 & .69 & 5.04 & .71 & 4.22 & .58 & 51 & $<.001$ \\
\hline Germany & 4.93 & .58 & 5.55 & .56 & 4.99 & .83 & 35 & $<.001$ \\
\hline Mexico & 4.55 & .78 & 4.88 & .71 & 3.34 & .44 & 57 & .001 \\
\hline Norway & 4.58 & .53 & 5.04 & .57 & 5.28 & .74 & 50 & $<.001$ \\
\hline Poland & 4.61 & .76 & 5.19 & .65 & 4.25 & .61 & 48 & $<.001$ \\
\hline South Africa & 4.53 & .66 & 4.90 & .73 & 4.06 & .56 & 51 & $<.001$ \\
\hline USA & 4.83 & .79 & 5.19 & .81 & 3.78 & .52 & 53 & $<.001$ \\
\hline \multicolumn{9}{|c|}{ Gender of participants: male } \\
\hline China & 4.84 & .68 & 5.21 & .78 & 3.83 & .49 & 59 & $<.001$ \\
\hline Germany & 4.70 & .57 & 4.80 & .65 & 0.80 & .12 & 40 & .43 \\
\hline Mexico & 4.45 & .72 & 4.56 & .81 & 1.04 & .14 & 54 & .30 \\
\hline Norway & 4.56 & .73 & 4.83 & .88 & 1.30 & .22 & 34 & .20 \\
\hline Poland & 4.44 & .66 & 4.43 & .82 & 0.06 & -.00 & 18 & .95 \\
\hline South Africa & 4.40 & .61 & 4.75 & .63 & 2.74 & .42 & 41 & .009 \\
\hline USA & 4.52 & .79 & 4.83 & .77 & 1.93 & .40 & 22 & .067 \\
\hline
\end{tabular}

Note: Mean comparisons were performed using $t$-tests for dependent measures and the $p$ values are two-tailed significance tests.

than men, $t(658)=2.60 ; p=.10 ; M_{\mathrm{f}}=4.68 ; S D_{\mathrm{f}}=0.88$; $M_{\mathrm{m}}=4.56 ; S D_{\mathrm{m}}=0.90$, but smiling men and women were found to be equally honest $\left(p=.46 ; M_{\mathrm{f}}=4.95\right.$; $\left.S D_{\mathrm{f}}=0.94 ; M_{\mathrm{m}}=4.98 ; S D_{\mathrm{m}}=0.95\right)$.

We also observed a culture*gender of participant interaction, $F(6,613)=3.60, p=.002, \eta_{\mathrm{p}}{ }^{2}=0.03$, indicating that not all females across cultures rated overall honesty of all targets higher than male participants (see Table 1). It seems that in some cultures (USA, Germany and Poland), women evaluated others as more honest than men, but in others (Norway, South Africa, China) no gender difference emerged.

All the remaining two-way interactions $(p>.25)$ as well as three-way interactions, culture*smile*gender of participant, $F(6,613)=1.50 ; p=.18$; other $p s>0.40$, and the four-way interaction $(p=.96)$ were not significant. Thus, we did not find cultural differences in perceptions of honesty of smiling and nonsmiling individuals.

\section{DISCUSSION}

Previous studies have suggested that people perceive smiling individuals as more communal in general, and more honest in particular, than individuals who do not smile (Krumhuber et al., 2007; Otta et al., 1994). In the present study, however, we demonstrated a gender difference in the perception of honesty in smiling individuals: Women assessed smiling individuals as more honest than men did, whereas there was no significant gender difference in the assessment of honesty in nonsmiling individuals.
Presented results were congruent with social norms theories indicating that social judgements may be affected by gender-based expectations. Women are expected to be more communal and expressive than men as well as more sensitive to emotional expressions of others (e.g., Brody \& Hall, 2008). Smiling increased women's perception of communal trait honesty of others, but this might not be the case with agency traits such as intelligence. Indeed, another study showed that there was no gender difference in evaluations of competence of smiling individuals (Krys et al., 2014). Thus, the effect seems to be specific to communal traits and thus not only due to women's more general positive responses to smiling faces.

The research on emotional contagion may deliver yet another but complementary explanation of our results. When exposed to facial expressions, females were more facially reactive than males. Particularly in response to happy faces, women smiled more than men (Dimberg \& Lundquist, 1990). This might provide them with facial feedback that in turn can make them feel better and translate into seeing others in a more favourable manner.

The only detected effect for target's gender was the two-way interaction with smile: Nonsmiling women were found to be more honest than men, but when all were smiling, this difference disappeared. This result may be explained by previously mentioned social norms theories (e.g., Brody \& Hall, 2008): As women are expected to be more communal and expressive than men, in the absence of explicit cues about communion (i.e., when targets were nonsmiling) women were found to be more honest; but when explicit cues about communion were delivered (targets were smiling), the assessed honesty of 
both men and women did not reflect gender stereotypes and all were perceived as honest. This is also in line with previous research showing that women were perceived as more communal and showed more emotions, but men's emotional expressions were less frequent and thus were perceived as more valid cues of their emotional states and traits more generally (Hutson-Comeaux \& Kelly, 2002).

The lack of the culture* smile interaction did not allow us to support the predictions about culture shaping the social perception of smiling individuals. We did not observe a combined influence of culture and gender on these perceptions (lack of culture*smile*gender interaction). Nevertheless, the collection of data in countries across five continents strengthened the presented gender*smile interaction.

Although the present research showed interesting differences in the perception of smiles and honesty, it has shortcomings. The weaknesses include a relatively small number of countries and not fully equivalent samples. For example, high and low diversity of incomes (e.g., South Africa vs. Norway) may influence the student samples used in our research. To provide stronger evidence for suggested explanations, data from other cultures are being collected. Further research will also help to verify our hypothesis on cultural diversity of the analysed phenomena.

We tested our predictions by presenting photographs to participants and asked them to evaluate the photographed individuals without giving any further information about the context or goal of this evaluation. As context and goals of evaluating others may influence perceptions and judgements of smiles (Niedenthal, Mermillod, Maringer, \& Hess, 2010), further studies should address other contextual and motivational factors that could influence the described effects.

Impression formation is based on processes that are fast, automatic and not fully conscious. Perception of honesty is one of the basic pre-conditions for sound social interactions. We believe that studying differences in the social perception of honesty in smiling individuals can help us to understand the basic mechanisms of impression formation as well as its cultural and gender specificities.

\section{REFERENCES}

Basabe, N., Páez, D., Valencia, J., Rimé, D., Pennebaker, J., Diener, E., \& González, J. (2000). Sociocultural factors predicting subjective experience of emotion: A collective level analysis. Psicothema, 12, 55-69.

Brody, L., \& Hall, J. (2008). Gender and emotion in context. In M. Lewis, J. Haviland-Jones, \& L. Feldman Barrett (Eds.),
Handbook of emotions (pp. 395-408). New York, NY: Guilford Press.

Dimberg, U., \& Lundquist, L. (1990). Gender differences in facial reactions to facial expressions. Biological Psychology, $30,151-159$.

Gonzaga, G., Keltner, D., Londahl, E., \& Smith, M. (2001). Love and the commitment problem in romantic relations and friendship. Journal of Personality and Social Psychology, 81, $247-262$.

Hall, J. (1984). Nonverbal sex differences: Communication accuracy and expressive style. Baltimore, MD: Johns Hopkins University Press.

Hess, U., Beaupré, M., \& Cheung, N. (2002). To whom and why - cultural differences and similarities in the function of smiles. In M. Abel (Ed.), The smile: Forms, functions, and consequences (pp. 187-216). New York, NY: The Edwin Mellen Press.

Hofstede, G. (2001). Culture's consequences: Comparing values, behaviors, institutions and organizations across nations. Thousand Oaks, CA: Sage.

House, R., Hanges, P., Javidan, M., Dorfman, P., \& Gupta, V. (Eds.) (2004). Culture, leadership, and organizations. The GLOBE study of 62 societies. Thousand Oaks, CA: Sage.

Hutson-Comeaux, S. L., \& Kelly, J. R. (2002). Gender stereotypes of emotional reactions: How we judge an emotion as valid. Sex Roles, 47(1-2), 1-10.

Krumhuber, E., Manstead, A., \& Kappas, A. (2007). Temporal aspects of facial displays in person and expression perception: The effects of smile dynamics, head-tilt, and gender. Journal of Nonverbal Behaviour, 31, 39-56.

Krys, K., Hansen, K., Xing, C., Szarota, P., \& Yang, M. (2014). Do only fools smile at strangers? Cultural differences in social perception of intelligence of smiling individuals. Journal of Cross-Cultural Psychology, 45, 314-321.

LaFrance, M., Hecht, M., \& Paluck, E. (2003). The contingent smile: A meta-analysis of sex differences in smiling. Psychological Bulletin, 129, 305-334.

Lau, S. (1982). The effect of smiling on person perception. Journal of Social Psychology, 117, 63-67.

Matsumoto, D., \& Kudoh, T. (1993). American-Japanese cultural differences in attributions of personality based on smiles. Journal of Nonverbal Behavior, 17, 231-243.

McClure, E. B. (2000). A meta-analytic review of sex differences in facial expression. Psychological Bulletin, 126, 424-453.

Minear, M., \& Park, D. (2004). A lifespan database of adult facial stimuli. Behavior Research Methods, Instruments, \& Computers, 36, 630-633.

Niedenthal, P., Mermillod, M., Maringer, M., \& Hess, U. (2010). The simulation of smiles (SIMS) model: Embodied simulation and the meaning of facial expression. Behavioural and Brain Sciences, 33, 417-433.

Otta, E., Lira, B., Delevati, N., Cesar, O., \& Pires, C. (1994). The effect of smiling and of head tilting on person perception. Journal of Psychology: Interdisciplinary and Applied, 128, $323-331$

Szarota, P. (2011). Smile: A user's manual. Barcelona, Spain: Editorial Aresta. 